\title{
Estimating the Glacier Contribution to Sea-Level Rise for the Period 1800-2005
}

\author{
P. W. Leclercq $\cdot$ J. Oerlemans $\cdot$ J. G. Cogley
}

Received: 16 December 2010/Accepted: 28 March 2011/Published online: 25 May 2011

(C) The Author(s) 2011. This article is published with open access at Springerlink.com

\begin{abstract}
In this study, a new estimate of the contribution of glaciers and ice caps to the sea-level rise over the period 1800-2005 is presented. We exploit the available information on changes in glacier length. Length records form the only direct evidence of glacier change that has potential global coverage before 1950. We calculate a globally representative signal from 349 glacier length records. By means of scaling, we deduce a global glacier volume signal, that is calibrated on the mass-balance and geodetic observations of the period 1950-2005. We find that the glacier contribution to sea-level rise was $8.4 \pm 2.1 \mathrm{~cm}$ for the period 1800-2005 and $9.1 \pm 2.3 \mathrm{~cm}$ for the period 1850-2005.
\end{abstract}

Keywords Sea-level rise · Glacier · Glacier length

\section{List of symbols}

$L \quad$ Glacier length (m)

$L_{1950}$ Glacier length in $1950(\mathrm{~m})$

$L^{*} \quad$ Normalised glacier length change w.r.t. $L_{1950}$

$\bar{L}^{*} \quad$ Mean of all normalised length change (w.r.t. $L_{1950}$ ) records

$\bar{L}_{13}^{*} \quad$ Mean of the 13 regionally stacked normalised length change records

$\bar{L}_{w 13}^{*} \quad$ Weighted mean of the 13 regionally stacked normalised length change records

$V^{*} \quad$ Normalised global glacier volume w.r.t. 1950

Electronic supplementary material The online version of this article (doi:10.1007/s10712-011-9121-7) contains supplementary material, which is available to authorized users.

P. W. Leclercq $(\square) \cdot$ J. Oerlemans

IMAU, Utrecht University, Princetonplein 5, 3584 CC Utrecht, The Netherlands e-mail: p.w.leclercq@uu.nl

J. Oerlemans

e-mail: j.oerlemans@uu.nl

J. G. Cogley

Department of Geography, Trent University, 1600 West Bank Drive, Peterborough,

ON K9J 7B8, Canada

e-mail: gcogley@trentu.ca 
$\Delta V \quad$ Absolute change in global glacier volume (cm sea-level equivalent)

$\eta \quad$ Exponent scaling length to volume

$S_{C} \quad$ Cumulative contribution of glacier to sea-level change as determined by MB data Cogley (2009) (cm)

$a, b \quad$ Regression coefficients

$\alpha, \beta \quad$ Scaling exponents relating glacier thickness and width to glacier length

\section{Introduction}

There is abundant evidence that eustatic sea level has been rising for at least the past two centuries (e.g. Church and White 2006; Jevrejeva et al. 2008; Cabanes et al. 2001; Warrick and Oerlemans 1990; Barnett 1983). Although the uncertainties are significant, the general view is that this rise has been between 15 and $25 \mathrm{~cm}$ for the period 1850-2000. This number is based on the analysis of tide gauge data, which do not provide a very good coverage of the oceans. Nevertheless, it appears that tide gauge and satellite data are broadly in agreement (e.g. Nicholls and Cazenave 2010), lending some credibility to the use of tide gauge data to infer sea levels further back in time. For the period 1993-2009, high precision altimetry from satellites shows that sea level rose by $3.3 \pm 0.4 \mathrm{~mm}_{\text {year }}{ }^{-1}$ (Nerem et al. 2010). This suggests that sea level rise is accelerating.

Finding the causes for the current sea-level rise is crucial. Thermal expansion of ocean water, changes in terrestrial storage of water, mass loss of ice caps and glaciers, and possible long-term imbalances of the mass budgets of the Greenland and Antarctic ice sheets have been listed as the most important processes contributing to the observed sealevel rise. The pressure, both scientific and political, to make estimates of future sea-level change has led to the use of so-called semi-empirical approaches in which a simple relation between past sea-level rate and temperature or radiative forcing is determined, and then extrapolated through the twenty-first century (e.g. Rahmstorf 2007; Grinsted et al. 2009; Vermeer and Rahmstorf 2009). The uncertainties in such an approach are large and the resulting potential errors in projections enormous. For instance, if a long-term contribution from the Antarctic ice sheet to sea-level rise were to be erroneously attributed to the melt of glaciers and ice caps, an empirically determined sensitivity parameter could be very inaccurate. To constrain models in a better way, the processes that cause sea-level change have to be quantified in the best possible way. In this paper we attempt to estimate the contribution of glaciers and ice caps since 1800 AD. Throughout this paper we mean by glacier contribution the contribution to sea-level change from all glaciers and ice caps outside the large ice sheets of Greenland and Antarctica. Included are the glaciers and ice caps on Greenland and Antarctica which are not part of or attached to the main ice sheets.

There are basically two approaches to estimate the loss of glacier ice over longer periods of time. The first approach is to use modelled climate sensitivity of glacier mass balance in combination with instrumental meteorological records of temperature and/or precipitation. It is assumed that the glacierised area does not change, and that the effect of climate change can simply be calculated by the combination of mass-balance sensitivity and climate perturbations. This approach was applied by Zuo and Oerlemans (1997) to 100 glacierized regions, allowing for the fact that glaciers in different climatic settings have different sensitivities. A major problem in this procedure is the definition of an initial state. One cannot just assume that at a certain point in time the state of any glacier is in balance with the prevailing climate. Zuo and Oerlemans (1997) showed that a difference ('climatic 
imbalance') of only $0.3 \mathrm{~K}$ between the real climate and the climate in which glaciers would have been in equilibrium has a large effect on the calculated contribution to sea-level change.

In the second approach one uses data on geometric changes of glaciers directly. This is attractive, because climate data are not needed as input and the problem of defining an initial state does not exist. However, other difficulties have to be handled. When going back in time over a few centuries, the only available geometric parameter is glacier length. The step from glacier length to glacier volume is not a trivial one and depends on the geographic setting. Lüthi et al. (2010) showed for 12 Swiss glaciers that, with the use of a simple glacier model, information on glacier length change can be used to calculate glacier volume changes. They also showed strong coherence of recorded length changes across the Swiss Alps. However, this method requires an equilibrium line altitude history and at least two volume measurements for each of the glaciers used in the study. A different solution is to calibrate volume changes calculated from length records by in situ mass-balance observations over the past 50 years. This method was exploited by Oerlemans et al. (2007) and will be extended in the current paper, by using a significantly larger number of glacier length records, and by involving more extensive in-situ mass balance and geodetic measurements (Cogley 2009).

In Sect. 2 the data sets used in this study are presented. In Sect. 3 we discuss some basic statistics of the glacier length records, consider the significance of regional variability, and discuss methods of normalization. In Sect. 4 we discuss the method to obtain a proxy for global glacier volume. In Sect. 5 the glacier contribution to sea-level change is then presented. Section 6 provides a discussion about uncertainties, a comparison to other estimates, and a summary of the results.

\section{Data}

\subsection{Glacier Length Variations}

The dataset on glacier length used in this study is an extension of the one used in Oerlemans et al. (2007). A number of records has been updated, and 152 records were added, mostly from remote areas like Greenland, Alaska, Central Asia and the southern Andes. The total number of records is 349 . Although there is a reasonable coverage of the land masses (Fig. 1), there are relatively few records from regions where much ice is found (Alaska, islands of the Arctic Ocean, Antarctica). There are no records from Antarctica or the arctic part of Canada and Russia, and only 8 from Greenland. In contrast, southern Europe (Pyrenees, Alps, Caucasus) has many records. Although there is an appreciable number of records from the Rocky Mountains, they are far from up-to-date: half of them have their last data points before 1990. Unlike North American records, most of the records in Patagonia continue up to 2005 at least, but 35 of the 54 records only start in 1945 . The mean starting date of the 349 records is 1867 , the mean end date 2001 (varying from 1534 to 1945 and from 1962 to 2009, respectively). The set of length records is divided into 13 regional subsets, following the division into regions by Radić and Hock (2010) (Table 1; Fig. 1). These subsets will be used to calculate a globally representative glacier signal.

The backbone of the data set is formed by Fluctuations of Glaciers data of the World Glacier Monitoring Service (WGMS 2008 and earlier volumes). Other sources are regular scientific publications, expedition reports, websites of glacier monitoring programs, and data supplied as personal communication. See the Supplementary Materials for details of 


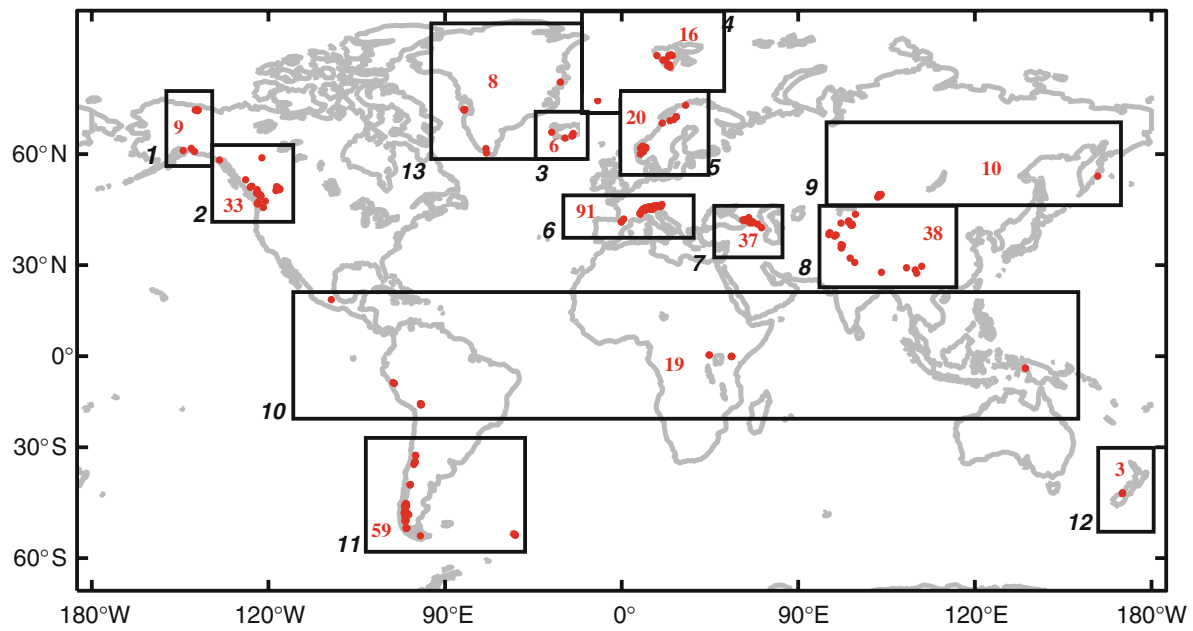

Fig. 1 Distribution of the glacier length records over the globe. In many cases the distance between glaciers is so small that the red dots overlap. The boxes depict the regions; the red number inside the boxes gives the number of records in the region; the number outside the box (in italics) gives the number of the region (cf. Table 1)

Table 1 The 13 regions from which glacier length records are available

\begin{tabular}{|c|c|c|c|c|c|c|}
\hline & Region & $\begin{array}{l}\# \text { of } \\
\text { records }\end{array}$ & $\begin{array}{l}\text { Area } \\
\left(\mathrm{km}^{2}\right)\end{array}$ & $\begin{array}{l}\text { Addition } \\
\left(\mathrm{km}^{2}\right)\end{array}$ & Weight & Comments \\
\hline 1 & Alaska & 9 & 79,260 & - & 0.1385 & \\
\hline 2 & Rocky Mountains & 33 & 21,480 & 73,345 & 0.1656 & Incl. half of Canadian Arctic \\
\hline 3 & Iceland & 6 & 11,005 & - & 0.0192 & \\
\hline 4 & $\begin{array}{c}\text { Jan Mayen, } \\
\text { Svalbard }\end{array}$ & 16 & 36,506 & 37,384 & 0.1291 & $\begin{array}{l}\text { Incl. Novaya Zemlya } \\
\text { and Franz Josef Land }\end{array}$ \\
\hline 5 & Scandinavia & 20 & 3,057 & - & 0.0053 & \\
\hline 6 & Alps and Pyrenees & 91 & 3,045 & - & 0.0053 & \\
\hline 7 & Caucasus & 37 & 1,397 & - & 0.0024 & \\
\hline 8 & Central Asia & 38 & 114,330 & - & 0.1997 & \\
\hline 9 & N. and E. Asia & 10 & 2,902 & 19,397 & 0.0390 & Incl. Severnaya Zemlya \\
\hline 10 & Tropics & 19 & 7,069 & - & 0.0123 & \\
\hline 11 & Southern Andes & 59 & 29,640 & 1,870 & 0.0550 & Incl. half of sub-Antarctic islands \\
\hline 12 & New Zealand & 3 & 1,156 & 1,870 & 0.0053 & Incl. half of sub-Antarctic islands \\
\hline 13 & Greenland & 8 & 54,400 & 73,345 & 0.2232 & Incl. half of Canadian arctic \\
\hline & Total & 349 & 362,193 & 210,265 & 1 & $\begin{array}{l}\text { Glaciers and ice-caps } \\
\text { on Antarctica not incl }\end{array}$ \\
\hline
\end{tabular}

Area is the total of ice-covered area within the region (Radic and Hock 2010), addition is the area that is added to this region, when we calculate the weight of the region. The total of added area is the area of glaciers and ice caps in regions in which we have no information on glacier length fluctuations

the individual records and references. Only records that start prior to 1945 are included in the data set. There are many more records available that start after 1950, but these were not included, because the main purpose of this study is to reconstruct the variations on a 
centennial time scale. Furthermore, records of glaciers that are known to be surging were excluded. The proportion of glaciers that surge is small, implying that their exclusion will hardly affect the representativeness of the data set.

In Fig. 2, examples of glacier length records are shown. Most of the records have data points with varying spacing in time. Before 1900 most data points are reconstructed on the basis of geomorphological or historical evidence, e.g. paintings, drawings, and descriptions. For European glaciers there is plenty of historical information, resulting in some detailed records (e.g. Zumbühl 1980; Nussbaumer et al. 2007) but, mostly, records have sparse data prior to 1900. From 1900 onwards, there is more information available worldwide, even annually for regions like Iceland, Norway, the Alps, and New Zealand. All records are interpolated with Stineman interpolation (Stineman 1980; Johannesson et al. 2009) to get annual values for the entire period covered by the record.

With Stineman interpolation the interpolated values are calculated from the values of the data points and the slopes at the gives points. The slope at a point is calculated from the circle passing through the point itself, the point before and the point after it. This method works well for series with uneven spacing between the data points, as is the case with the glacier length records. Moreover, it has the advantage that it produces no spurious minima or maxima not prescribed by the data.

In this paper we consider glacier length changes relative to the glacier length in 1950 $\left(L_{1950}\right)$, and we use normalised glacier length changes, defined as:

Fig. 2 Examples of glacier length records from different parts of the world. Each dot represents a data point. Data points are connected by means of Stineman interpolation. See Supplementary Material for references to the sources of the individual records

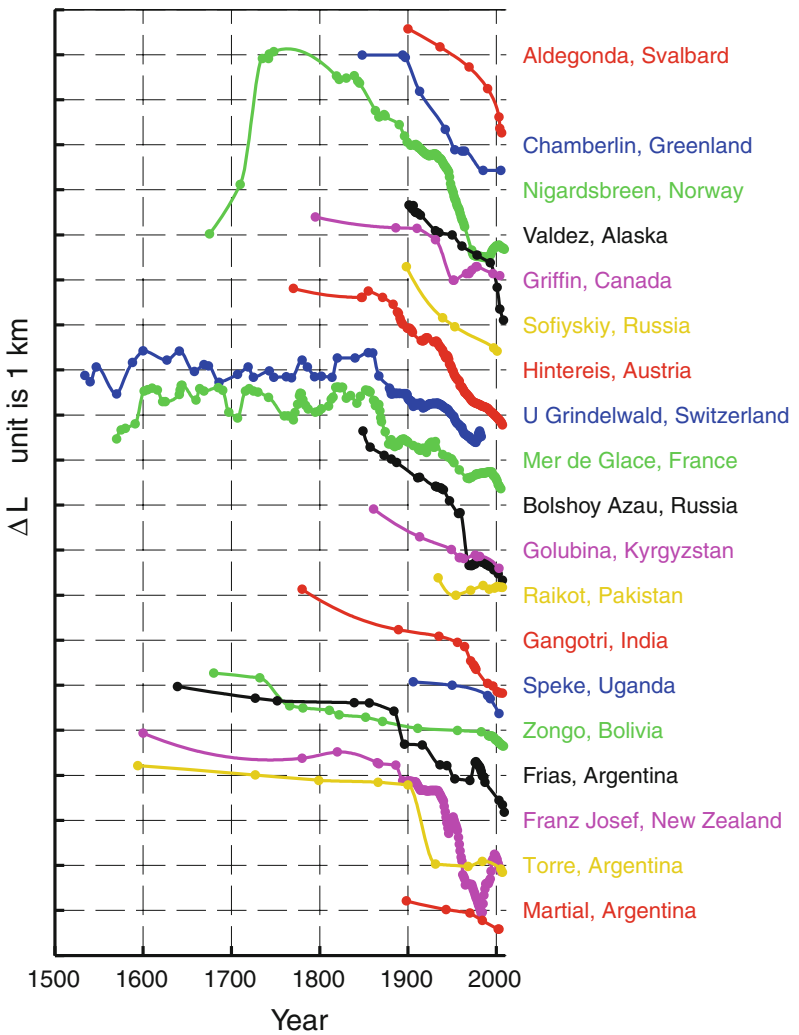




$$
L^{*}(t)=\frac{L(t)-L_{1950}}{L_{1950}} .
$$

The length of the glacier is taken from the WGMS, the World Glacier Inventory (National Snow and Ice Data Center 1999, update 2009), or the same source as the length record of the glacier. These glacier length measurements are made in different years for different glaciers. For all glaciers, $L_{1950}$ is calculated from the measured glacier length and the length change between 1950 and the year of measurement. If the record has no data point in 1950, the length change is calculated from the interpolated length record. As we will show, the normalised length change can be used to reconstruct a globally coherent glacier length signal. Thus it will play a key role in the reconstruction of the volume change of all glaciers and small ice caps.

\subsection{Global Glacier Mass Balance}

Global averages of measured mass balances for 1950/1951 to 2008/2009 are taken from an update of the compilation of Cogley (2009). The dataset includes 2,905 balance-years of measurements by glaciological methods on 355 glaciers, and 13,671 balance-years of measurements by geodetic methods on 359 glaciers. Most of the glaciological measurements are of annual mass balance, while most of the geodetic measurements cover several to many years. The joint analysis of these disparate data, including a procedure for generating annual pseudo-series of geodetic mass balance with estimates of uncertainty, is explained by Cogley (2009).

The annual glaciological time series are serially uncorrelated. This finding is exploited by calculating pentadal averages of the annual estimates, which reduces uncertainty by a factor of $1 / \sqrt{5}=0.45$. To address the problem of spatial bias, with some ice-covered regions well represented while others have no measurements at all, the pentadal averages are interpolated to the centres of the 1301 glacierized cells of a $1^{\circ} \times 1^{\circ}$ grid.

The interpolation algorithm is explained in more detail by Cogley (2004). Briefly, the interpolation function is a polynomial, fitted by least squares, in the two horizontal coordinates of an azimuthal equidistant projection centred at each cell in turn. During the interpolation, the pentadal averages of the measurements are weighted by a suitable distance-decay function, which is derived from an analysis of the spatial autocorrelation of annual glaciological time series. The distance scale for loss of correlation between these time series is close to $600 \mathrm{~km}$, as shown by Cogley and Adams (1998). For each cell, the interpolated estimate is the first coefficient of the polynomial (its intercept on the massbalance axis) and its uncertainty is the standard error of that coefficient as estimated by the least-squares procedure. The global average for each pentad is the sum of the $1^{\circ} \times 1^{\circ}$ cell estimates, and its uncertainty is the root-sum-square of the cell uncertainties, each weighted by the glacierized area of each cell. The uncertainty of the glacierized areas is allowed for by conventional propagation of errors. Glacierized cells around the periphery of Antarctica are not included in the interpolation, and their contribution to the global average is obtained by upscaling the estimate for the rest of the world, following Kaser et al. (2006).

The total of the global glacierized area used in this paper amounts to $704,000 \mathrm{~km}^{2}$ and is the glacierized area contained in the grid cells plus the glacierized area around the periphery of Antarctica. This total area is smaller than the $741,000 \mathrm{~km}^{2}$ used in Radic and Hock (2010), who relied on an older estimate of the glacierized area in Antarctica outside the ice sheet proper. 


\section{Regional and Global Length Records}

\subsection{Regional Glacier Length Changes}

As the examples in Fig. 2 show, the glacier records display a consistent signal over the globe. The curves differ in details like amplitude of the signal and fluctuations on decadal time scale, but the overall picture is rather uniform. There is a clear world-wide retreat of glaciers that started in the middle of the nineteenth century. The general retreat since this time is further illustrated by Fig. 3. Here the average rate of length change of the available records is shown for four different periods: 1801-1850, 1851-1900, 1901-1950, and 1951-2000. From 1801-1850, the majority of the glaciers had a small to moderate retreat, but a substantial proportion, $28 \%$, of the glaciers advanced. Therefore the median retreat rate for this period is just slightly negative, namely $-0.9 \mathrm{ma}^{-1}$. For all three periods after 1851, the median rate of change is more negative: $-5.8,-10.3$, and $-8.9 \mathrm{ma}^{-1}$ for the periods 1851-1900, 1901-1950, and 1951-2000, respectively. In these periods the number of average advances is very small, namely less than $5 \%$.

For each of the 13 regions, we have calculated the average length change from the records within the region. Fig. 4a shows these regional glacier length records after smoothing with a weighted running average filter, with 21 -year width. This smoothing is

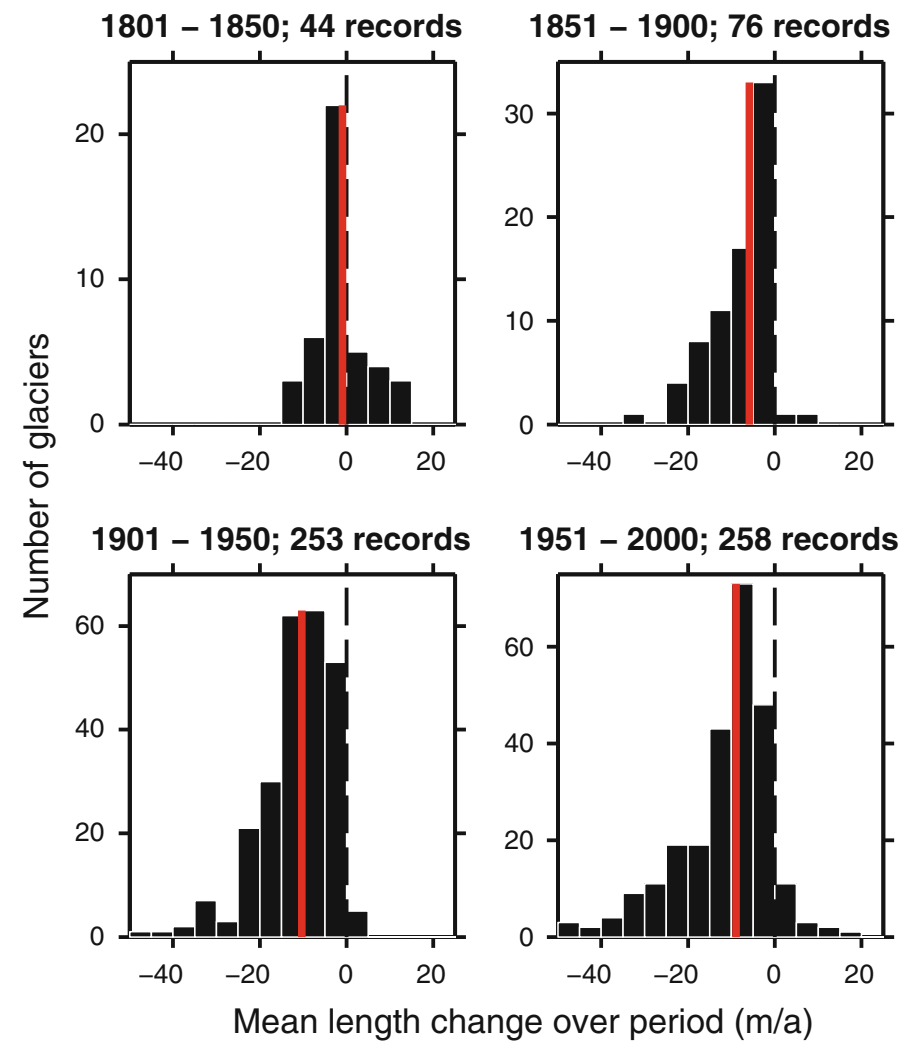

Fig. 3 Averaged rate of length change for four different periods. The vertical red line indicates the median rate of length change. Note the changing number of records for each period 
Fig. 4 a Stacked glacier length records for the different regions. The length change is with respect to the length in 1950. In b the normalised length records are shown. The clear outlier is the average of the tropical glaciers, region 10 . See Table 1 and Fig. 1 for the further corresponding regions
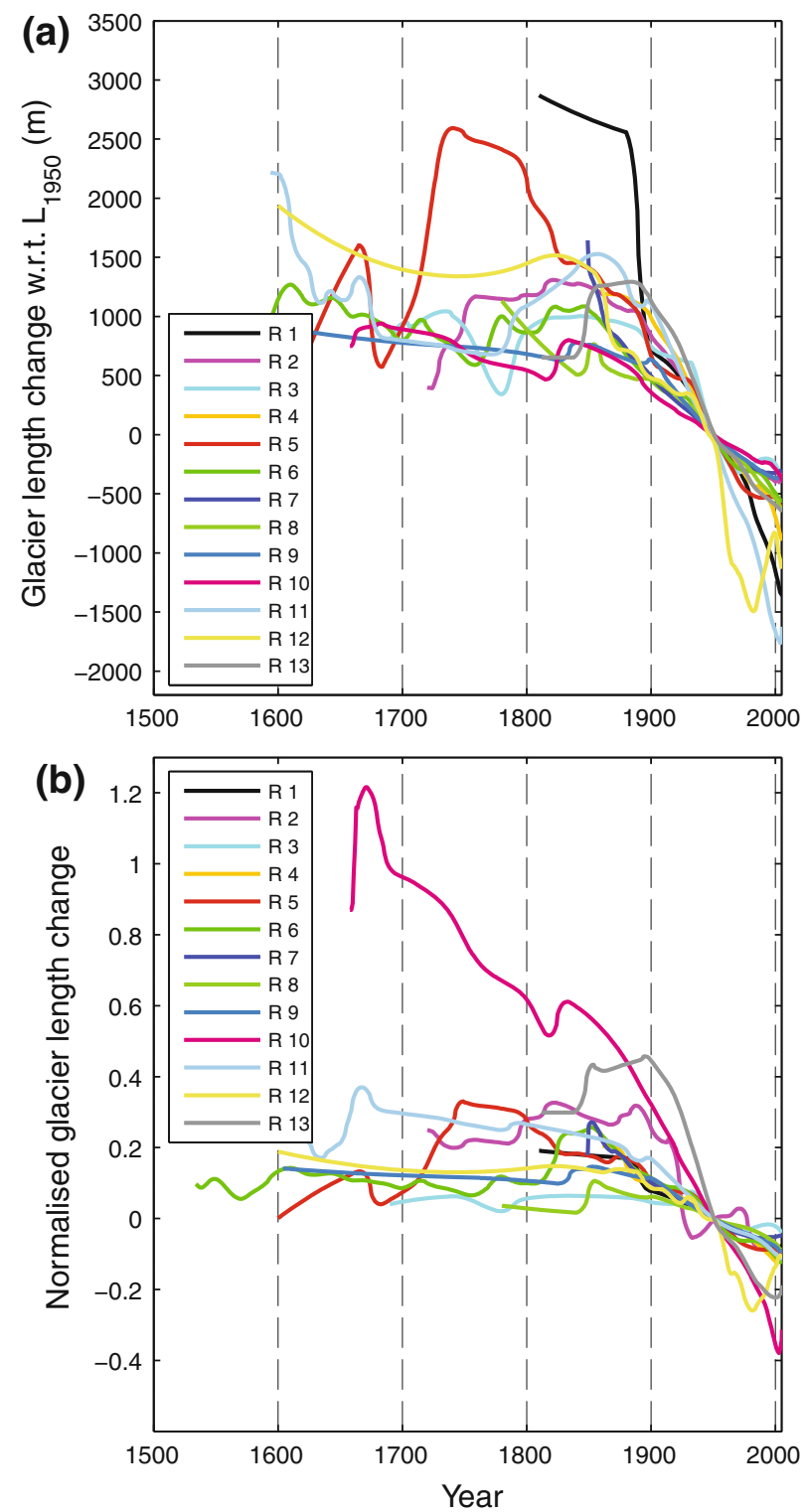

necessary because jumps in the stacked record are created when a record enters the stack or when a record in the stack ends. The stacked records of the regions start at different years, varying from 1534 (Alps, region 6) to 1861 (Svalbard and Jan Mayen, region 4), but all stacked records continue to 2004 at least. Furthermore, the glacier retreat since the middle of the nineteenth century in all regions is clearly visible. However, the amount of length change over the covered period is variable.

We have also calculated the average normalised length change for each region, using Eq. 1. The resulting stacked records are shown in Fig. 4b, again smoothed with a 21-year weighted running average filter. The tropical glaciers (region 10) are a clear outlier, with a 
large relative change. In general, the tropical glaciers are rather small, and they have significantly retreated over the past centuries. Especially the glaciers on Irian Jaya (Carstenz and Meren) have very large relative retreats (and have now almost disappeared), but also the glaciers in Central Africa and Bolivia have become much smaller. The smallest relative length changes have occurred in regions 3, 6, and 8 (Iceland, Alps, and Central Asia). In general the variability in the normalised stacked records is smaller than the variability in the stacked records, shown in Fig. 4a. This can be explained by the fact that larger glaciers are flatter and therefore more sensitive to climate change (Oerlemans 2005); the length and climate sensitivity compensate each other when we use the relative length change.

\subsection{The Global Signal}

The goal of this study is to develop a globally representative proxy for ice volume from the available glacier length records. This is done following the method of Oerlemans et al. (2007). As discussed above, the normalised length records have more coherency than the length records. Therefore, we use the normalised length records to construct a proxy for global ice volume. Moreover, most of the records come from regions where the ice cover is relatively small (notably the Alps and Caucasus). To obtain a globally representative length signal we have to apply a weighting procedure that reduces the effect of overrepresentation of regions with many records. We achieve this by averaging the stacked records of the 13 regions. The result is shown in Fig. 5a.

Fig. 5 a The global length signal from normalised glacier length records for three different averaging methods: mean of all records $\bar{L}^{*}$ (black), mean of the 13 regions $\bar{L}_{13}^{*}($ red $)$, and the weighted average of the 13 regions $\bar{L}_{w 13}^{*}($ blue). b Total number of available records (dashed grey), and cumulative weight of the regions that have at least one record (black line); the weights of the individual regions are given in Table 1
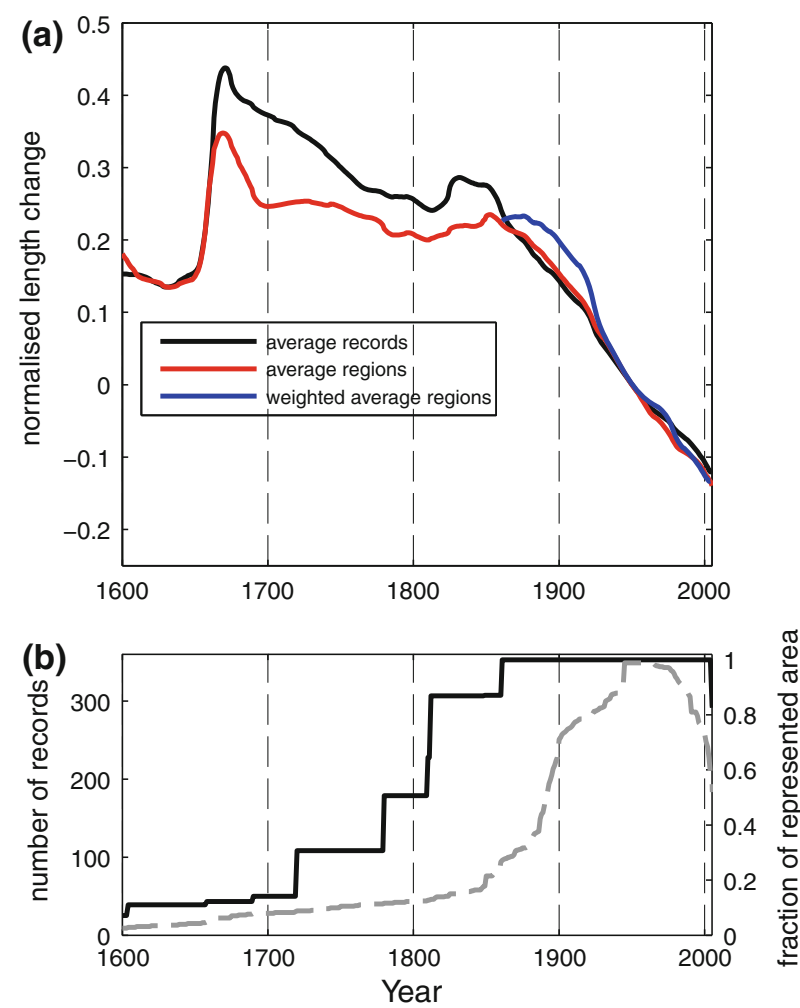
The black line is the average normalised length record of all available records $\left(\bar{L}^{*}\right)$. In this average the large relative retreat of the tropical glaciers (see Fig. 4b) is clearly visible. The mean of all regions, with equal weights, $\left(\bar{L}_{13}^{*}\right)$ then yields the red curve in Fig. 5a. After 1860 , the two different averages are very similar, although $\bar{L}_{13}^{*}$ reveals a larger glacier retreat during the period 1960-2000. Before 1850, the records differ significantly due to the suppression of the tropical signal in the regional average.

A third approach $\left(\bar{L}_{w 13}^{*}\right)$ is to give the regions different weights, proportional to the area covered by glaciers in the regions. In principle, this is the best method to construct a proxy from the glacier length records that is representative for the ice volume. It removes the bias generated by the fact that we have more regions with smaller glaciers. The ice-covered area of the regions is taken from Radić and Hock (2010) (Table 1). To obtain weights, the icecovered area not covered by the 13 regions is distributed over the regions that could plausibly represent the regions devoid of records (column labelled "addition" in Table 1). We have not included the area of Antarctic glaciers; we have no representative region with glacier length records. We have to assume that their behavior is similar to the behavior of the global signal we deduce from the other regions. In fact, this procedure reveals the weakness of the data set on glacier length fluctuations; little to nothing is known in regions with large amounts of ice, like the Canadian arctic and the Russian arctic islands. From Table 1 it is clear that the average is mainly determined by regions $1,2,4,8$, and 13 . It only makes sense to construct $\bar{L}_{w 13}^{*}$ for the period in which the sum of the represented area equals the total area, or is at least close to it. The fraction of the represented area, which equals the cumulative weight of the regions with records available in that year, is given in Fig. 5b. Before 1861 the total weight is less than $90 \%$, so we have calculated $\bar{L}_{w 13}^{*}$ for the period 1861-2004, shown with the blue line in Fig. 5a. However, we should keep in mind that the number of records in the dominating regions is limited until the beginning of the twentieth century.

$\bar{L}^{*}, \bar{L}_{13}^{*}$, and $\bar{L}_{w 13}^{*}$ appear to be remarkably similar throughout the twentieth century. This finding reflects that (1) the relative change in glacier length has been comparable for smaller and larger glaciers and (2) the behavior of glaciers over the past century has been coherent over the globe. Before 1900, the similarity between the different averages is smaller, but we should keep in mind that here the number of records is limited, especially for the regions with a large weight. It would be most appropriate to base the proxy for world-wide glacier volume on $\bar{L}_{w 13}^{*}$. However, this would limit the period of the reconstruction, and, in the second half of the nineteenth century, the reconstruction would rely heavily on just a few records. As $\bar{L}_{w 13}^{*}$ and $\bar{L}_{13}^{*}$ are very similar, we base the glacier volume proxy on $\bar{L}_{13}^{*}$. This will be worked out in the next section.

\section{Proxy for Glacier Volume}

\subsection{Scaling Glacier Volume to Glacier Length}

To use the global glacier length signal to deduce the changes of glacier volume, we have to relate glacier length to glacier volume. There exist scaling theories relating the length of a single glacier to its volume (e.g. Bahr et al. 1997), but it is not entirely evident how this scaling of individual glaciers should be translated to a global average. Here, we follow the approach of Oerlemans et al. (2007). The ice volume scales with the ice thickness, the length and the width of a glacier (cf. Bahr et al. 1997): 


$$
[V]=[H][L][W] .
$$

Based on results from analytical and numerical glacier modeling, we can assume a scaling relation between the normalised ice thickness and the glacier length:

$$
\frac{H}{H_{\text {ref }}}=\left(\frac{L}{L_{\text {ref }}}\right)^{\alpha},
$$

where $H$ is the mean ice thickness, $L$ the glacier length or ice-cap radius and the subscript "ref" indicates a reference state. For a glacier on a flat bed with ice that deforms perfectly plastically the mean ice thickness is proportional to the square root of the glacier length, i.e. $\alpha=0.5$ (Weertman 1961). From numerical models, using the shallow ice approximation, values in the range 0.40 to 0.44 are found, depending on the slope of the bed (Oerlemans 2001). Next we assume that the length and the width of a glacier are also related through a power law, with exponent $\beta$. Then it follows for the normalised volume:

$$
\frac{V}{V_{\text {ref }}}=\left(\frac{L}{L_{\text {ref }}}\right)^{1+\alpha+\beta} \text {. }
$$

We use $L_{1950}$ as reference length, such that the normalised glacier volume can be written in terms of normalised length change $L^{*}$ using Eq. 1:

$$
\frac{V}{V_{1950}}=\left(\frac{L}{L_{1950}}\right)^{1+\alpha+\beta}=\left(1+L^{*}\right)^{1+\alpha+\beta} .
$$

We assume a similar scaling as for individual glaciers can be used for the normalised global glacier length signal $\bar{L}_{13}^{*}$. Thus, the normalised global ice volume $V^{*}$ can be expressed as:

$$
V^{*}=\left(1+\bar{L}_{13}^{*}\right)^{\eta}
$$

where $\eta=1+\alpha+\beta$, and ranges from 1.4, for glaciers for which a change in volume does not affect the glacier width $(\beta=0)$, to 2.5 , for ice caps that can expand freely in all directions $(\beta=1)$. Based on the analysis of the geometry of more than 300 glaciers by Bahr et al. (1997), the most likely average value for $\eta$ is 2.0 to 2.1. Note that according to expressions 1 and 6 the non-dimensional volume equals unity in 1950, the reference year for the length changes. We consider $V^{*}$ to be the best possible glacier volume proxy derived from the set of glacier length records, with $\eta$ within the 1.4-2.5 range, but probably close to 2.0. $V^{*}$ is again smoothed with a 21 -year filter to smooth out jumps created in the volume when new regions enter the $\bar{L}_{13}^{*}$ average.

\subsection{Calibration of Glacier Volume Proxy}

To estimate the glacier contribution to sea-level rise, we need to translate the normalised glacier volume $V^{*}$ into actual glacier volume change. Therefore, we calibrate the reconstructed glacier volume change on the compilation of mass balance data of Cogley (2009), that gives the changes in global ice mass for the period 1951-2009 (see Sect. 2.2). We denote the cumulative contribution to sea-level change as determined from the mass balance measurements by $S_{C}$. The calibration of $V^{*}$ on $S_{C}$ is simply done with a linear regression (least squares) such that: 


$$
\Delta V=a+b V^{*}=-S_{C},
$$

where $\Delta V$ is expressed in terms of sea-level equivalent. The regression is calculated for the period 1951-2005, because after 2005 the numbers of glacier length and mass-balance records are considered to be too small.

As explained in Sect. 2.2, the uncertainty in the total mass balance is calculated from the variance of the available measurements. However, although formally correct, this calculation underestimates the true uncertainty. Uncertainties due to the fact that not all regions are represented in the mass balance measurements, and in particular the uncertainty in the upscaling to Antarctica, are not taken into account. Furthermore, in the conversion of specific mass balance to ice volume change, the total ice-covered area is kept constant. In order to get a more realistic estimate of the uncertainty in the reconstructed contribution of glaciers to sea-level change, we have calculated upper and lower bounds of $S_{C}$ by assuming that:

1. In 1950 about half of the ice-covered area is represented in the mass balance series, this fraction increases linearly to $75 \%$ in 1980, and stays constant after 1980 .

2. The unrepresented ice has on average experienced half of the measured loss, which gives the lower bound, or,

3. the unrepresented area has experienced an average mass balance of 1.5 times that of the measured record, which gives the upper bound.

The resulting upper and lower bounds of the cumulative total mass balance are shown as dashed black lines in Fig. 6. The range in the cumulative total mass balance series is used to estimate an uncertainty band for $\Delta V$. We recalculate $\Delta V$, by calibrating it on the upper and lower estimate of $S_{C}$. The differences between $\Delta V_{\text {upper }}$ and $\Delta V_{\text {lower }}$ on the one hand and $\Delta V$ on the other (calculated while setting the difference in 2005 to zero), give an uncertainty range for the contribution of glaciers to sea-level change reconstructed from glacier length changes.

\section{Results}

After the calibration of $\Delta V$ on $S_{C}$, the glacier contribution to sea-level change can be extended backwards in time (Fig. 6). Since the number of records before 1800 and after

Fig. 6 Reconstructed contribution of glaciers and icecaps to sea-level rise. The cumulative mass balance record is given in black (Cogley 2009); the reconstructed sea-level change from the glacier length records is shown in red. The range of the upper and lower estimates is indicated with dashed black lines for the mass balance record and with red uncertainty bars for the reconstruction from glacier lengths

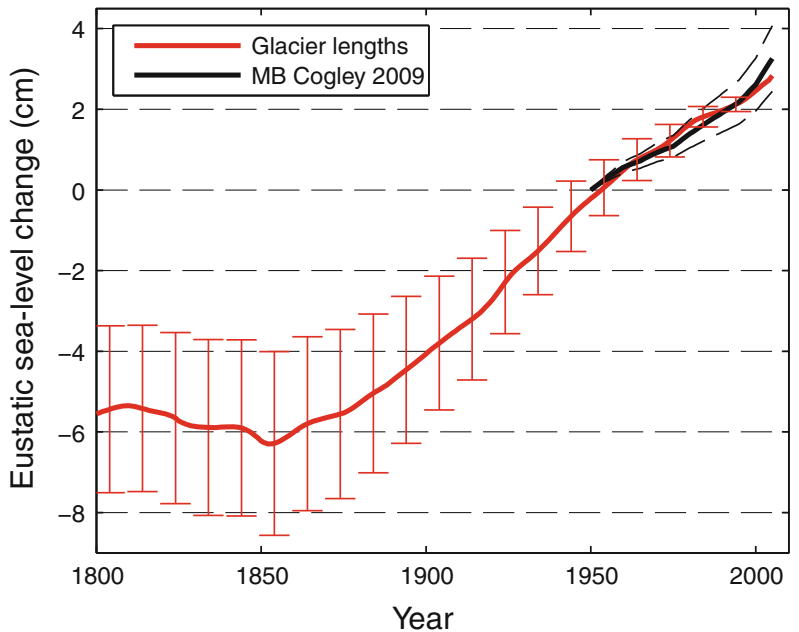


2005 is very limited (Fig. 5b), the reconstruction is only shown for the period 1800-2005. We have found the contribution of glaciers to be $8.4 \pm 2.1$ for the period 1800-2005, with a maximum of $9.1 \pm 2.3 \mathrm{~cm}$ between 1850 and 2005. The uncertainties in these estimates are derived from the result we obtain when we calibrate to the lower and upper estimate of the mass balance series. These uncertainties are substantial, following from the assumed range in the mass balance measurements. The cumulative total mass balance of all glaciers and ice-caps is calculated to be $3.2 \pm 0.8 \mathrm{~cm}$ sea-level equivalent for the period 1950-2005.

As shown earlier by Oerlemans et al. (2007), the reconstructed contribution is hardly dependent on the choice of the scaling parameter $\eta$, as can be seen in Fig. 7a. The estimates of sea-level rise over the period 1850-2005 differ by about $1 \mathrm{~cm}$ for a range $\eta$ from 1.4 to
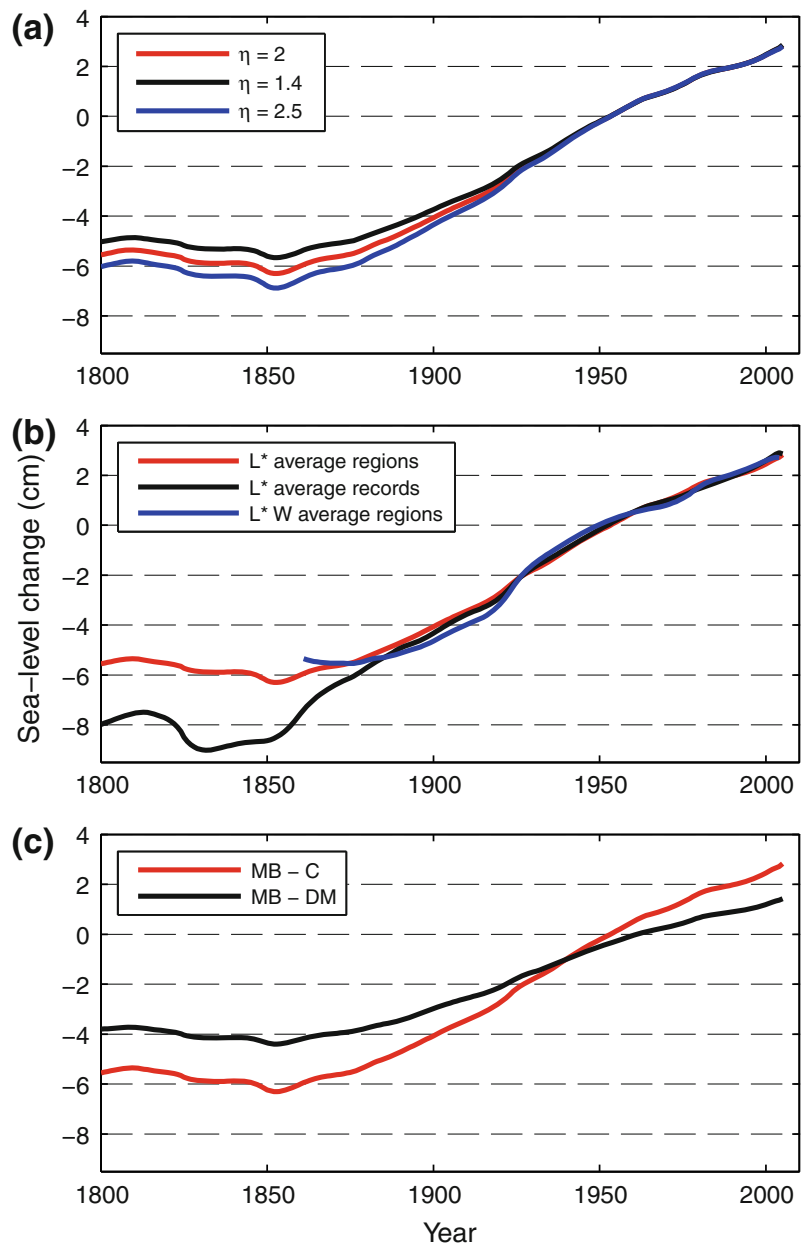

Fig. 7 Sensitivity of the reconstructed sea-level change to the choice of parameters; in each figure the best estimate shown in Fig. 6 is displayed in red. a Sensitivity to different values of the scaling constant $\eta$; b global ice volume change (sea-level equivalent) calculated from the different global length signals shown in Fig. 5a; c The global ice volume calibrated on the mass balance record of Cogley (2009) (MB-C, as used in this study) and of Dyurgerov and Meier (2005) [MB-DM, as used in Oerlemans et al. (2007)] 
2.5. This is a wide range, covering the range of assumptions from the width of all glaciers being constant for any change of volume, to all glaciers being unbounded ice caps. Hence, the choice of the scaling parameter is not critical. It should be noted that for every choice of $\eta$ the regression constants $a$ and $b$ in Eq. 7 are different.

The reconstructed sea-level change is more sensitive to the calculation of the global length signal (Fig. 7b) and the mass balance data (Fig. 7c). For the two global length signals derived from regional averages, $\bar{L}_{13}^{*}$ and $\bar{L}_{w 13}^{*}$, the results are almost the same. If we use $\bar{L}_{w 13}^{*}$ for the reconstruction of $\Delta V$, the decrease in the ice volume seems to start later, at the end of the nineteenth century. Of course, this result is not conclusive as this record does not go far back in time and the number of records in the regions with large weight is limited (as was already stressed in Sect. 3.2, this is the reason we use $\bar{L}_{13}^{*}$ ). Using $\bar{L}^{*}$ gives a much larger contribution to sea-level change. Before the marked increase in the number of records in the second half of the nineteenth century, the relative contribution of the tropical glaciers to this global signal is much higher than in the other two averages. As the tropical glaciers are outliers in the normalised length change signal (see Fig. 4b), this results in an increased sea-level change.

If we calibrate $\Delta V$ on the mass balance data set compiled by Dyurgerov and Meier (2005), we get a substantially smaller estimate of the contribution of glaciers to sea-level change. The result is then very close to the 5-6 cm for the period 1850-1900 found by Oerlemans et al. (2007), who used this data set. This shows that our result is sensitive to the uncertainties in the global mass balance record on which $\Delta V$ is calibrated.

\section{Conclusion and Discussion}

\subsection{Uncertainty}

The data on glacier area, as summarized in Table 1, do not directly affect our estimate of the glacier contribution to sea-level rise. This information was only used to verify that $L_{13}^{*}$ can be used as a proxy for global ice volume variations. The fact that the regional averages of normalised length change present a rather homogeneous picture, with the notable exception of the tropical glaciers, is a consequence of the coherent behavior of glaciers over the globe on a centennial time scale. This also explains the fact that, if we use the mass balance record of Dyurgerov and Meier (2005) (Fig. 7c), the reconstructed contribution based on the current data set of 349 glaciers is very similar to the results of Oerlemans et al. (2007), who used only 197 records. The difference between the results of this study and of Oerlemans et al. (2007) can thus mainly be attributed to the extended mass balance series of Cogley (2009), who noted that the newly-assimilated geodetic mass balances in this compilation were on average more negative than those in earlier compilations. However, this total mass balance, and thus the reconstruction of glacier sea-level contribution, is sensitive to the distribution of the global ice cover. In this study, the calculation of the total mass balance and the corresponding total ice-volume change is based on the gridded data set of Hock et al. (2009), with a total glacier area of 704,000 $\mathrm{km}^{2}$, instead of the regional data set of Radic and Hock (2010) used for the weighted average of the global length signal.

As shown in Fig. 7a, our result is not very sensitive to the value of $\eta$ used in the volumelength scaling. The difference in the calculated sea-level contribution is within $1 \mathrm{~cm}$, for values of $\eta$ ranging from 1.4 to 2.5 . This is a very wide range. Therefore, we expect that assigning $\eta$ and applying volume scaling to individual glaciers, rather than to the global 
average length signal, will not substantially reduce the uncertainty in the reconstructed contribution. This would in addition require information on the geometry of all glaciers in the length data set. This information is not available at present.

Fundamental to our approach is the assumption that both the global length signal $L_{13}^{*}$ and the global cumulative mass balance record $S_{C}$ are truly globally representative. Several regions with large amounts of ice are not represented in the glacier length data set (Table 1; Fig. 1). This introduces an uncertainty in the global length signal, although we think that the glacier length signal is spatially rather coherent. The same holds for the mass balance measurements. The relative error in the reconstructed contribution of glaciers to sea-level change is approximately proportional to the error in the glacier contribution calculated from the mass balance series for the period 1950-2005. It is difficult to quantify these uncertainties, so we have shown (Fig. 6) the results with rather large uncertainty range of $25 \%$. This gives a best estimate for the contribution of glaciers to sea-level change for the period 1850-2005 of $9.1 \pm 2.3 \mathrm{~cm}$ eustatic sea-level equivalent. The best estimate shows a minimum in 1850 , but as the uncertainty bars indicate, the significance of this minimum should not be overestimated. The number of length records as well as their global coverage is limited in the first half of the nineteenth century.

\subsection{Comparison to Earlier Results}

Earlier studies of the contribution of glaciers to sea-level change on a centennial timescale (Oerlemans et al. 2007; Gregory and Oerlemans 1998; Zuo and Oerlemans 1997; Meier 1984) all give smaller estimates than our results. Except for Oerlemans et al. (2007), all estimates are based on calculated mass balances. Meier (1984) calculated the contribution for the period 1900-1961. Based on very few measured volume changes and mass balance series he arrived at a contribution of $2.8 \pm 1.6 \mathrm{~cm}$, whereas we have calculated a contribution to sea-level rise of $4.7 \pm 1.8 \mathrm{~cm}$ for the same period.

Zuo and Oerlemans (1997) and Gregory and Oerlemans (1998) calculated mass balance sensitivities for glaciers distributed over 100 different regions; the sensitivity was dependent on the characteristic precipitation (mean annual precipitation on the glaciers) in the region and a distinction was made between sensitivity to changes in summer temperatures and non-summer temperatures. Based on measured temperature data, Zuo and Oerlemans (1997) found a contribution of glaciers to sea-level rise of $2.7 \pm 0.9 \mathrm{~cm}$ for the period 1865-1990. Based on the same mass balance sensitivities but using temperatures calculated with a general circulation model, Gregory and Oerlemans (1998) found a contribution of 1.9 or $3.3 \mathrm{~cm}$ for the period 1860-1990, depending on the climate scenario. These estimates are significantly lower than the estimate presented in this study; we have calculated a contribution to sea-level rise of $8.0 \pm 2.2 \mathrm{~cm}$ for the period 1860-1990. Our twofold to fourfold greater estimate can partly be explained by the difference in the total area of all glaciers: Zuo and Oerlemans (1997) used 527,900 $\mathrm{km}^{2}$, excluding the glaciers around Greenland (those were included in the contribution of the Greenland ice sheet) and Antarctica. Instead, we use the more recent estimate of $704,000 \mathrm{~km}^{2}$, used in Cogley (2009), which includes glaciers in Greenland and Antarctica. Secondly, and more importantly, Zuo and Oerlemans (1997) have underestimated the characteristic precipitation in most of the 100 regions. This leads to lower values for the mass balance sensitivity, and thus to a too low estimate of the volume loss of glaciers. Slangen et al. (manuscript in preparation) show, with the use of the precipitation from an ensemble of twelve climate 
models and accounting for the difference in total glacier area, that the results of the mass balance sensitivity approach are comparable to the results presented in this study.

Compared to our results, Oerlemans et al. (2007) estimated a smaller contribution for the period 1850-2000, and their best estimate showed a more pronounced minimum in the contribution around 1850. The difference in the reconstructed contribution for the period 1850-2000 is almost entirely due to the training data set $S_{C}$ (see Sect. 5 and Fig. 7c). The disappearance of the pronounced maximum is due to the additional glacier length data.

\subsection{Concluding Summary}

In this study we have calculated the contribution of glaciers and ice caps to sea-level change of the last two centuries from geometric changes of glaciers. Length change is the only glacier property for which information goes far back in time. Hence, we have reconstructed a global volume signal from glacier length using a scaling relation. The global length signal is derived from the average of 13 regions. This can be done, because glaciers show a worldwide coherent signal. We have calibrated the thus derived glacier volume changes on the total mass balance of the period 1950-2005. This gives a maximum sea-level contribution for the period 1850-2005 of $9.1 \pm 2.3 \mathrm{~cm}$ and a best estimate for the contribution over the period 1800-2005 of $8.4 \pm 2.1 \mathrm{~cm}$. This contribution is larger than previously estimated. According to our estimate, $35-50 \%$ of the observed sea-level rise since 1800 is due to melt of glaciers and ice caps.

Acknowledgments We would like to thank A. Slangen, R. van de Wal and two anonymous reviewers for their useful comments.

Open Access This article is distributed under the terms of the Creative Commons Attribution Noncommercial License which permits any noncommercial use, distribution, and reproduction in any medium, provided the original author(s) and source are credited.

\section{References}

Bahr DB, Meier MF, Peckham SD (1997) The physical basis of glacier volume-area scaling. J Geophys Res 102(B9):20355-20362

Barnett TP (1983) Recent changes in sea level and their possible causes. Clim Change 5:15-38

Cabanes C, Cazenave A, Provost CL (2001) Sea level rise during past 40 years determined from satellite and in situ observations. Science 294(5543):840-842. doi:10.1126/science.1063556

Church JA, White NJ (2006) A 20th century acceleration in global sea-level rise. Geophys Res Lett 33(L01602). doi: 10.1029/2005GL024826

Cogley JG (2004) Greenland accumulation: an error model. J Geophys Res 109(D18101). doi: 10.1029/2003JD004449

Cogley JG (2009) Geodetic and direct mass-balance measurements: comparison and joint analysis. Ann Glaciol 50(50):96-100

Cogley JG, Adams WP (1998) Mass balance of glaciers other than the ice sheets. J Glaciol 44(147):315-325

Dyurgerov M, Meier MF (2005) Glaciers and the changing earth system: a 2004 snapshot. Occasional paper no. 58, INSTAAR. University of Colorado

Gregory JM, Oerlemans J (1998) Simulated future sea-level rise due to glacier melt based on regionally and seasonally resolved temperature changes. Nature 391:474-476

Grinsted A, Moore JC, Jevrejeva S (2009) Reconstructing sea level from paleo and projected temperatures 200 to 2100 AD. Clim Dyn 34(4):461-472. doi:10.1007/s00382-008-0507-2

Hock R, de Woul M, Radic V, Dyurgerov M (2009) Mountain glaciers and ice caps around Antarctica make large sea-level rise contribution. Geophys Res Lett 36. doi:10.1029/2008GL037020 
Jevrejeva S, Moore J, Grinsted A, Woodworth P (2008) Recent global sea level started over 200 years ago? Geophys Res Lett 35(L08715). doi:10.1029/2008GL033611

Johannesson T, Bjornsson H, Grothendieck G (2009) Package 'stinepack'. Icelandic Meteorological Office

Kaser G, Cogley JG, Dyugerov MB, Meier MF, Ohmura A (2006) Mass balance of glaciers and ice caps: consensus estimates for 1961-2004. Geophys Res Lett 33(L19501). doi:10.1029/2006GL027511

Lüthi MP, Bauder A, Funk M (2010) Volume change reconstruction of Swiss glaciers from length change data. J Geophys Res 115(F0402). doi: 10.1029/2010JF001695

Meier MF (1984) Contribution of small glaciers to global sea level. Science 226(4681):1418-1421

National Snow and Ice Data Center (1999) World glacier inventory. World Glacier Monitoring Service and National Snow and Ice Data Center/World Data Center for Glaciology, Boulder (update 2009)

Nerem RS, Chambers DP, Choe C, Mitchum GT (2010) Estimating mean sea level change from the TOPEX and Jason altimeter missions. Mar Geodesy 33(1):435-446. doi:10.1080/0190419.2010.491031

Nicholls RJ, Cazenave A (2010) Sea-level rise and its impact on coastal zones. Science 328:1517. doi: 10.1126/science.1185782

Nussbaumer SU, Zumbühl HJ, Steiner D (2007) Fluctuations of the "Mer de Glace" (Mont Blanc area, France) AD 1500-2050: an interdisciplinary approach using new historical data and neural network simulations. Zeitschrift für Gletscherkunde und Glazialgeologie 40:1-183

Oerlemans J (2001) Glaciers and climate change. AA Balkema Publishers

Oerlemans J (2005) Extracting a climate signal from 169 glacier records. Science 308:675-677

Oerlemans J, Dyurgerov M, van de Wal RSW (2007) Reconstructing the glacier contribution to sea-level rise back to 1850 . The Cryosphere 1(1):59-65

Radić V, Hock R (2010) Regional and global volumes of glaciers derived from statistical upscaling of glacier inventory data. J Geophys Res 115(F01010). doi:10.1029/2009JF001373

Rahmstorf S (2007) A semi-empirical approach to projecting future sea-level rise. Science 315:368. doi: 10.1126/science. 1135456

Stineman RW (1980) A consistently well-behaved method of interpolation. Creative Comput 54-57

Vermeer M, Rahmstorf S (2009) Global sea level linked to global temperature. PNAS 106(51): 21527-21532. doi:10.1073/pnas.0907765106

Warrick RA, Oerlemans J (1990) Sea level rise. In: Climate change-IPCC scientific assessment. Cambridge University Press, Cambridge, pp 257-281

Weertman J (1961) Stability of ice-age ice-sheets. J Geophys Res 66:3783-3792

WGMS (2008) Fluctuations of glaciers, vol I-IX. ICSU (FAGS)/IUGG (IACS)/UNEP/UNESCO/WMO, World Glacier Monitoring Service, Zurich, Switzerland (earlier volumes)

Zumbühl HJ (1980) Die Schwankungen der Grindelwaldgletscher in den historischen Bild- und Schriftquellen des 12. bis 19. Jahrhunderts. Birkhäuser, Basel

Zuo Z, Oerlemans J (1997) Contribution of glacier melt to sea-level rise since AD 1865: a regionally differentiated calculation. Clim Dyn 13:835-845 